Research Article

\title{
Preparation of Mesoporous Biochar from Cornstalk for the Chromium (VI) Elimination by Using One-Step Hydrothermal Carbonation
}

\author{
Chao Wang $\mathbb{D},{ }^{1}$ Jun Xie $\mathbb{D}^{1},{ }^{1}$ Mingdong Zheng $\mathbb{D}^{1},{ }^{1}$ Jinbo Zhu $\mathbb{D}^{1},{ }^{1}$ and Changliang Shi $\mathbb{D}^{2}$ \\ ${ }^{1}$ Department of Materials Science and Engineering, Anhui University of Science \& Technology, Huainan, China \\ ${ }^{2}$ College of Chemistry and Chemical Engineering, Henan Polytechnic University, Jiaozuo, China \\ Correspondence should be addressed to Jun Xie; jxie@aust.edu.cn
}

Received 18 May 2021; Revised 17 August 2021; Accepted 16 September 2021; Published 5 October 2021

Academic Editor: Alessandro Buccolieri

Copyright (c) 2021 Chao Wang et al. This is an open access article distributed under the Creative Commons Attribution License, which permits unrestricted use, distribution, and reproduction in any medium, provided the original work is properly cited.

Hydrothermal carbon (HTC) was prepared by the one-step hydrothermal method for Cr (VI) removal from wastewater, which was considered a "green chemistry" method. The specific surface area $\left(\mathrm{S}_{\mathrm{BET}}\right)$ of HTC was $85 \mathrm{~m}^{2} / \mathrm{g}$ with the pore size in range of 2.0-24.0 nm. FT-IR spectra analysis showed that the HTC had abundant chemical surface functional groups. The influence of adsorption parameters such as $\mathrm{pH}, \mathrm{HTC}$ dosage, $\mathrm{Cr}$ (VI) concentration, and contact time on the removal efficiency of Cr (VI) had been investigated. When the initial concentration was $50 \mathrm{mg} / \mathrm{L}, \mathrm{pH}=6$, amount of adsorbent was $0.2 \mathrm{~g} / 50 \mathrm{ml}$, and adsorption time was 90 min; the $\mathrm{Cr}$ (VI) absorbed rate of HTC reached 98\%. Batch adsorption experiments indicated that Cr (VI) adsorption data of HTC fitted the Freundlich isothermal and pseudo-second-order kinetic models. Overall, our findings provide a promising material in treatment of $\mathrm{Cr}(\mathrm{VI})$-rich wastewater and give a clear picture of its application, which is worthy of further study.

\section{Introduction}

Heavy metal contamination in water is becoming a concerning global environmental issue. Heavy metal pollutants, such as chromium, arsenic, cadmium, nickel, copper, and lead, are difficult to be removed or degraded from the water mostly due to their high stability [1]. Among these heavy metals, chromium was noticed as a hazardous pollutant introduced by multiple industrial processes including electroplating, leather tanning, pigment, and production paint [2]. In wastewater, chromium existed principally with two comparatively stable forms including hexavalent $\mathrm{Cr}$ (VI) and trivalent $\mathrm{Cr}$ (III) $[3,4]$, in which $\mathrm{Cr}$ (VI) was relatively hazardous than $\mathrm{Cr}(\mathrm{III})$, especially in the human body $[5,6]$. Moreover, Cr (VI) revealed a nature of absorption and accumulation within human bodies such as the stomach, kidneys, and liver especially, which caused the severe somatic damages [5, 7-9].

Massive efforts focused on precipitation, electrochemical recovery, solvent extraction, membrane separation, and ion exchange had been devoted to eliminating Cr (VI) from industry wastewaters [10-14]. However, numerous approaches were indicated as invalid and expensive, which led to secondary pollution to the environment as a consequence in some cases [15]. Adsorption had been regarded as the most effective method aiming to eliminate the contaminants within the aqueous systems [16]. Hence, the investigation in appropriate adsorbent emerged the importance of developing a considerable adsorption technology [16, 17]. Activated carbons have better adsorption capacity and $\mathrm{Cr}$ (VI) absorbed rate resulted from the large surface area and volume, which have been widely employed to eliminate $\mathrm{Cr}$ (VI) ions from wastewater resulted from its low cost, high adsorption efficiency, and simple operation [18, 19]. Unfortunately, activated carbons are commonly prepared via chemical or physical activation methods. In general, biomass materials were employed as precursors [20], which require high energy consumption and cause damage to the environment [21-23]. Therefore, it is particularly important to find a synthesis method with low energy consumption. 
Recently, hydrothermal carbonization (HTC) processes as a nascent technology to produce functional materials was reported resulting from its low cost, simplicity in operation, and high energy efficiency $[24,25]$. One was also be classified as "green" because no organic solvents or surfactants were needed in the treatment process [25].

Biochar is produced from agriculture and forest waste which contain mainly carbon. Biochar-type materials have raised increasing attention attributed to their unique mesoporous structure, high ion exchange capacity, and high specific surface which allow them to be widely used for applications in greenhouse gas reduction, soil improvement, and remediation of contaminated soil [26-28]. Guo et al. reported the $\mathrm{Cr}$ (VI) adsorption on the HTC prepared from rice husk at $650-850^{\circ} \mathrm{C}$ and found adsorption efficiency is related to the micoporous and mesoporous [29]. Anandkumar and Mandal used AC prepared from bael fruit at $600^{\circ} \mathrm{C}$ to eliminate $\mathrm{Cr}$ (VI) with a considerable value of $17.27 \mathrm{mg} / \mathrm{g}$ in adsorption capacity that had been acquired [30]. Also, several activated carbon adsorbents from agricultural and biological wastes including almond shells, straw, waste tea, coconut shells, cactus leaves [31, 32], and algae had been introduced in chromium (VI) elimination from water solutions. However, the production process of biochar is relatively complex. The biomass was first preheated at low temperature and followed by chemical activation. Last, the biomass was hydrothermally carbonized at high temperatures such as 600,800 , and even $1000^{\circ} \mathrm{C}$.

In this work, the mesoporous biochar was acquired using one-step hydrothermal carbonization from cornstalk at relatively mild temperature conditions $\left(190^{\circ} \mathrm{C}\right)$ at self-generated pressures. The effects of several important operating parameters on the removal of $\mathrm{Cr}$ (VI) from aqueous solution, such as $\mathrm{pH}$, adsorption dosage, initial concentration of the solution, and contact time, were studied by batch experiments. Furthermore, the adsorption kinetics and isotherms of $\mathrm{Cr}$ (VI) on HTC at different temperatures were also analyzed and discussed.

\section{Experimental}

2.1. Materials. The raw material of this experiment is corn straw, which was collected in Huainan City, Anhui Province. TGA, EDS, and XRD of corn straw are shown in Figures 1(a), 1(b), and 1(c), respectively. According to the TGA curve, the weight loss of corn straw can be divided into three stages: A (gasification stage), B (thermal cracking stage), and $\mathrm{C}$ (carbonization stage). The decomposition temperature exceeds $200^{\circ} \mathrm{C}$ and has thermal stability. The characteristic peaks of $\mathrm{C}$ and $\mathrm{O}$ elements in EDS showed that the main component of corn straw was cellulose. The XRD diffraction pattern shows that the diffraction peak is $14.8^{\circ}$, $16.5^{\circ}$, and $22.5^{\circ}$, representing (101) and (002) crystal planes of cellulose type I crystal structure, respectively, indicating that the crystal structure has not changed. Cornstalk was acquired from local natural resources and was cleaned and dried to constant weight at room temperature. Sulfuric acid (98 wt.\%), phosphoric acid, sodium hydroxide, acetone, potassium dichromate, and analytical grade 1,5- diphenylcarbazide were acquired from Beijing Chemical Reagents Company. Potassium dichromate $\left(\mathrm{K}_{2} \mathrm{Cr}_{2} \mathrm{O}_{7}\right)$ with a certain quantity was dissolved into deionized water to prepare the stock solution and then diluted to the required concentration for further analysis.

2.2. Synthesis of HTC. Different synthesis methods of HTC were considered [32-34]. The preparation of biomass porous carbon usually requires a high temperature calcination process [21-23], while our hydrothermal carbon (HTC) is prepared by a one-step hydrothermal method, which is much simpler. A representative process is selected, as shown in Figure 2. $15 \mathrm{~g}$ corn stalk had been dissolved into $80 \mathrm{~mL}$ of dilute sulfuric acid $(1.84 \mathrm{M})$ with stirring to form a homogenous solution. The mixture was subsequently removed to $120 \mathrm{~mL}$ Teflon-lined stainless steel autoclave and then placed in an electronic heating furnace (preheated at $190^{\circ} \mathrm{C}$ ) for $12 \mathrm{~h}$. After cooled to room temperature, the solid product was gathered by a filter flask and cleaned by a deionized ethanol solution. HTC products had been dried in a vacuum oven at $120^{\circ} \mathrm{C}$ for $8 \mathrm{~h}$.

2.3. Characterization Techniques. The porous texture of the HTC was analyzed by $\mathrm{N}_{2}$ sorption at $-196^{\circ} \mathrm{C}$, using an automatic adsorption system (Quanta Chrome, America). Before measurements, the sample was degassed at $120^{\circ} \mathrm{C}$ for $5 \mathrm{~h}$. The specific surface area of the sample was calculated by the Brunauer-Emmett-Teller (BET) method using the adsorption data at the relative pressure $\left(P / P_{o}\right)$ range of $0.05-0.3$. The total pore volume was calculated at $P / P_{\mathrm{o}}=0.99$, and the pore size distribution curve was computed using the BJH model.

Infrared spectra $\left(5000-0 \mathrm{~cm}^{-1}\right)$ were recorded using a Bruker VERTEX 70 FT-IR spectrometer. The sample was prepared by mixing an oven-dried (at $105^{\circ} \mathrm{C}$ ) sample with spectroscopy-grade $\mathrm{KBr}$ in an agate mortar.

The HTC sample was dried in a fan-forced oven under air at $80^{\circ} \mathrm{C}$. About $0.1-0.2 \mathrm{~g}$ of each sample was weighed into tin foil cups and combusted with an oxygen catalyst at $1150^{\circ} \mathrm{C}$. The ultimate analyses were conducted on a Thermo Scientific FLASH 2000 autoanalyzer.

Powdered HTC sample was placed onto the adhesive carbon tape on an aluminum stub followed by sputter coating with gold. The surface morphology of the sample was observed on a UL-TRA55 scanning electron microscope (SEM) operated at $2 \mathrm{kV}$.

2.4. Adsorption Experiments. Adsorption characteristic had been achieved under the batch mode at $35^{\circ} \mathrm{C}$. First, a certain amount of $1 \mathrm{M} \mathrm{HCl}$ and $1 \mathrm{M} \mathrm{NaOH}$ had been applied to modify the $\mathrm{pH}$ value of each solution followed by mixed with the adsorbent. The influence of $\mathrm{pH}$ on the adsorbability of HTC had been illustrated to determine an optimal $\mathrm{pH}$ value. The effects of initial adsorbate concentration, dosage, and contacting duration on the adsorption performance were then studied at the optimum $\mathrm{pH}$. The adsorbent was employed to mix with $50 \mathrm{~mL}$ of adsorbate solutions with a 


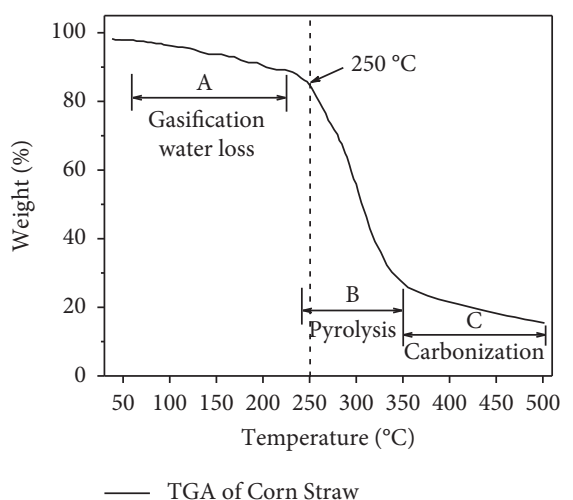

(a)

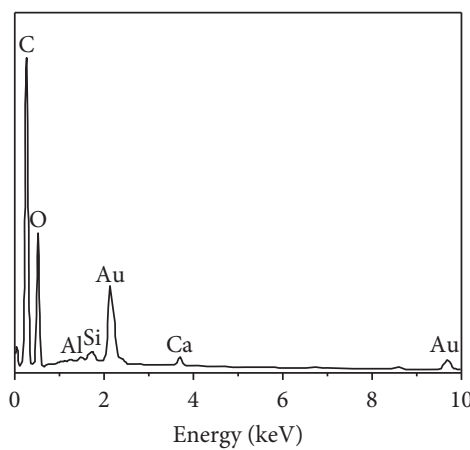

EDS of Corn Straw

(b)

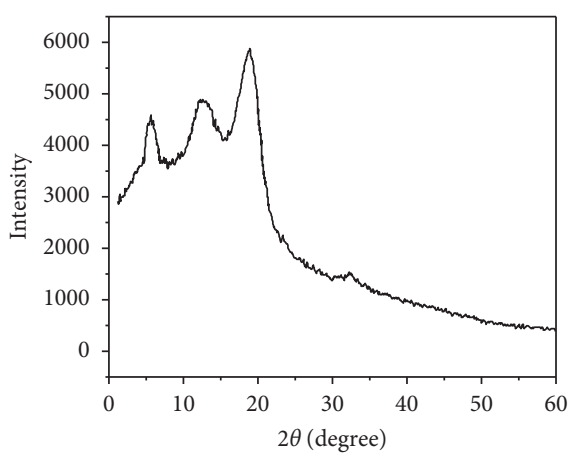

(c)

FIgure 1: The TGA (a), EDS (b), and XRD (c) curves of corn straw.

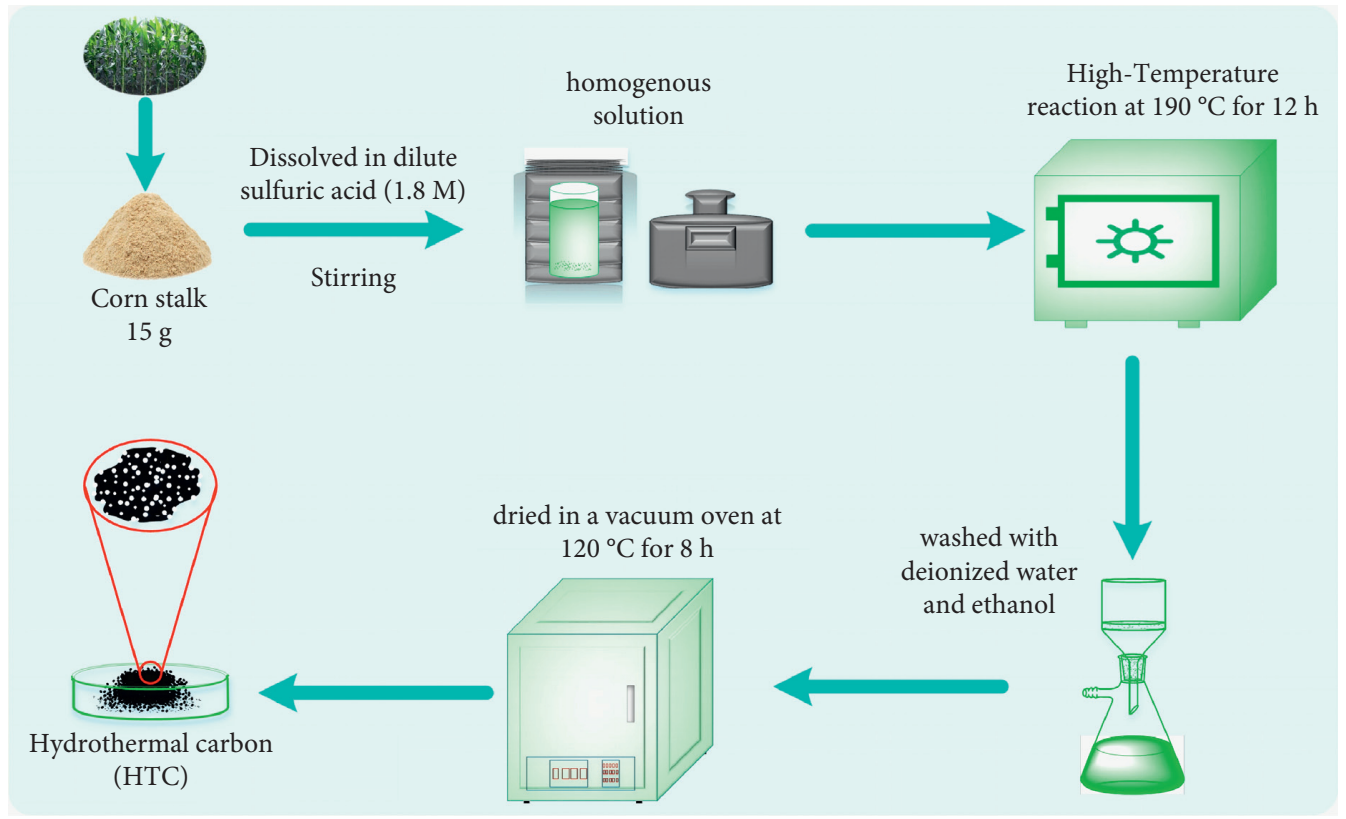

Figure 2: Synthesis process of the HTC.

particular initial concentration. Specimens were designed to be collected at different intervals of time, and the adsorbents were extracted by filtration. Whereafter, the filtrates had been investigated in the residuary chromium (VI) concentration with the UV spectrophotometer (TU-1880, Beijing, China) under the wavelength of $540 \mathrm{~nm}$. The amount of adsorbed had been evaluated via the following equation:

$$
q=\frac{v\left(c_{0}-c_{t}\right)}{m}
$$

where $q$ is the amount of $\mathrm{Cr}$ (VI) ions adsorbed per unit gram of hydrothermal carbon $(\mathrm{mg} / \mathrm{g})$ at any time $(t), c_{t}$ is the final $\mathrm{Cr}(\mathrm{VI})$ concentration after a certain period $(\mathrm{mg} / \mathrm{L}), c_{0}$ is the initial $\mathrm{Cr}(\mathrm{VI})$ concentration $(\mathrm{mg} / \mathrm{L})$, and $v$ is the initial solution volume (L); $m$ is the HTC mass (g). The percentage of removed metal ions in the solution was calculated using the following equation:

$$
\eta=\frac{\left(c_{0}-c_{t}\right)}{c_{0}}
$$

\section{Results and Discussion}

3.1. Pore Structure Characterization. The curves of the pore size distribution (PSD) and corresponding nitrogen adsorption-desorption isotherm for HTC samples are shown in Figure 3. According to the IUPAC classification, it can be seen from Figure 1(a) that the HTC exhibits a type IV isotherm curve. There was no significant increase in nitrogen uptake when the relative pressure was below 0.01 , the apparent increase in nitrogen adsorption at the range from 0.1 to 1.0 in relative pressure, and the capillary hysteresis loop indicates the existence of developed mesoporous structure in the sample. Figure 3(b) shows its pore size distribution in 2.0-24.0 $\mathrm{nm}$, in which multiple peaks are shown, indicating 


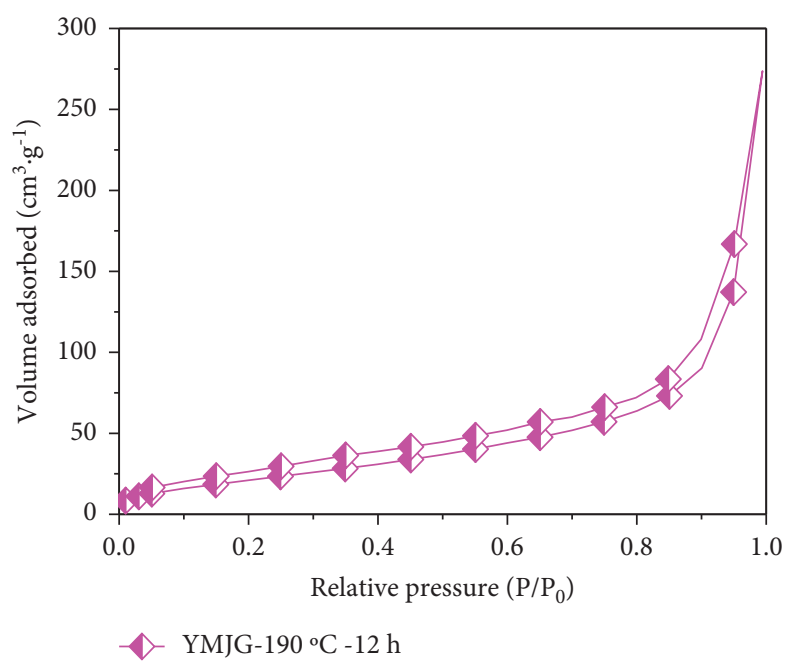

(a)

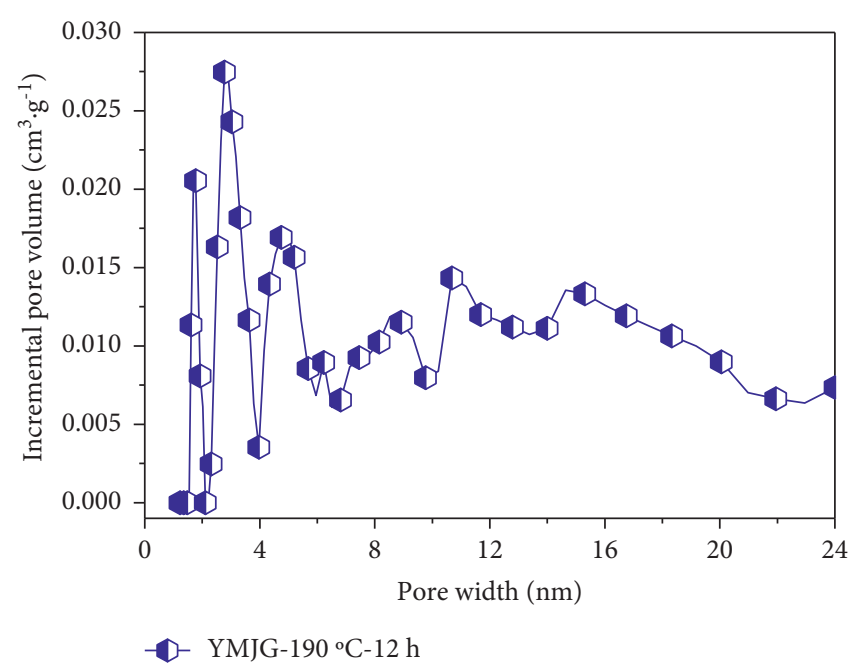

(b)

Figure 3: $\mathrm{N}_{2}$ adsorption-desorption isotherms (a) and pore sizes distribution curves (b) of YMJG.

that the HTC has a broad size distribution. Table 1 provides the textural characteristics of the HTC which exists an $\mathrm{S}_{\mathrm{BET}}$ and overall pore volume $\left(V_{\mathrm{t}}\right)$ of $85 \mathrm{~m}^{2} / \mathrm{g}, 0.042 \mathrm{~cm}^{3} / \mathrm{g}$, respectively. These values are even higher than the reports in some kinds of literature $[35,36]$ at higher hydrothermal temperatures. The large $S_{\mathrm{BET}}$ and broad distribution of pore size is necessary for the $\mathrm{Cr}(\mathrm{VI})$ ions reaching the interior of the material, thus achieving maximum absorption.

3.2. FT-IR Spectra and Ultimate Analyses of the HTCCornstalk. Structure analysis of the HTC-cornstalk at the initial and end states of the adsorption had been revealed via FT-IR spectra and is shown in Figure 4. O-H (bonded) stretching vibration is correlative to the band between 3700 and $3030 \mathrm{~cm}^{-1}$. Moreover, peaks of 2929 and $2376 \mathrm{~cm}^{-1}$ implied the stretching vibration of $\mathrm{C}-\mathrm{H}$ and $\mathrm{C}-\mathrm{N}$, respectively, while 1700 and $1600 \mathrm{~cm}^{-1}$ were associated with $\mathrm{C}=\mathrm{O}$ and $\mathrm{C}=\mathrm{C}$ stretching [36]. The absorption band between 995 and $1242 \mathrm{~cm}^{-1}$ is attributed to the C-O stretching vibration of esters, aliphatic, or alcohols [37]. Band at $620 \mathrm{~cm}^{-1}$ was corresponded to the aromatic ring $(\mathrm{C}-\mathrm{H})$ bending vibration [38]. After adsorption, the peaks at 3450, 2929, and $2376 \mathrm{~cm}^{-1}$ shift towards a lower wavenumber of 3429,2918 , and $2355 \mathrm{~cm}^{-1}$, respectively. The absolute values of bands between 1700 and $1600 \mathrm{~cm}^{-1}$ are smaller after adsorption. This suggests that there were possible interactions between these groups and $\mathrm{Cr}(\mathrm{VI})$. However, the absolute values of the band at 1112 and $640 \mathrm{~cm}^{-1}$ become larger, which indicates that the HTC-cornstalk has higher functional groups after $\mathrm{Cr}$ (VI) adsorption. One is given in Table 2, in which the carbon content was increased during the HTC process, whereas the oxygen and hydrogen contents were decreased, which is consistent with other reports $[39,40]$.

3.3. SEM Analysis. The SEM images of HTC-cornstalk at different magnifications are shown in Figures 5(a) and 5(b), respectively. It can be observed that the uniform spheres were formed on the surface of the sample. This may be because the HTC synthesized from cornstalk was not completely carbonized [41]. This phenomenon is interesting due to fact that some porosity structures could be formed during the hydrothermal carbonization of biomass materials under common conditions [41-43]. Figure 5(a) shows that there are some pores formed on the surface of the sample. Besides, many small spheres cover the inner wall of the aperture (Figure $5(\mathrm{~b})$ ). The reason is that the cornstalk underwent isomerization, fragmentation, dehydration, polymerization, and carbonization to form the spheres on the surface of the sample [44].

\subsection{Batch Adsorption Studies}

3.4.1. Effect of $p H$ and HTC-Cornstalk Dosage. At the range of 1.0-9.0 in $\mathrm{pH}$ values of the solution, $\mathrm{Cr}$ (VI) absorption induced by $\mathrm{HTC}$ at $35^{\circ} \mathrm{C}$ had been observed. Figure 6(a) uncovers the impact of the $\mathrm{pH}$ value on $\mathrm{Cr}(\mathrm{VI})$ adsorption under the conditions of $50 \mathrm{mg} / \mathrm{L}$ in the initial $\mathrm{Cr}$ (VI) concentration and $90 \mathrm{~min}$ in the contacting duration. The adsorbability sharply decreases with the increase of the $\mathrm{pH}$ value from 4.0 to 9.0 which implied the strong correlation between adsorbing behaviors of $\mathrm{Cr}(\mathrm{VI})$ and the $\mathrm{pH}$ value of the solution. Only $22 \% \mathrm{Cr}$ (VI) ions had been eliminated in the case of $\mathrm{pH}=9$ instead of over $82 \%$ while in a slightly acidic solution with $\mathrm{pH}=6.0$. Moreover, an even higher removal rate of the $\mathrm{Cr}$ (VI) ions of $98 \%$ had been achieved when the $\mathrm{pH}$ value was 1.0. The surface functional groups in the adsorbent and metal solution chemistry are highly related to the $\mathrm{pH}$, which can largely affect metal adsorption ability $[40,45,46]$. Under the strong acid condition, the removal rate of $\mathrm{Cr}$ (VI) ion was higher; however, it would bring acid pollution to the environment. Thus, the optimum $\mathrm{pH}$ for the adsorption experiment is chosen as 6 .

The effect of the adsorbent dosage was also investigated at $35^{\circ} \mathrm{C}$, as shown in Figure $6(\mathrm{~b})$. Results indicated that the removed $\mathrm{Cr}(\mathrm{VI})$ ions quantity was enlarged as the 
TABLE 1: Textural characteristics.

\begin{tabular}{lccccc}
\hline Sample & $\begin{array}{c}\text { Specific surface } \\
\text { area }\left(\mathrm{m}^{2} \cdot \mathrm{g}^{-1}\right)\end{array}$ & $\begin{array}{c}\text { Total pore } \\
\text { volume }\left(\mathrm{cm}^{3} \cdot \mathrm{g}^{-1}\right)\end{array}$ & $\begin{array}{c}\text { Micropore } \\
\text { volume }\left(\mathrm{cm}^{3} \cdot \mathrm{g}^{-1}\right)\end{array}$ & $\begin{array}{c}\text { Mesopore } \\
\text { rate }(\%)\end{array}$ & $\begin{array}{c}\text { Average pore size } \\
(\mathrm{nm})\end{array}$ \\
\hline HTC & 85 & 0.42 & 0.003 & 99.93 & 3.41 \\
\hline
\end{tabular}

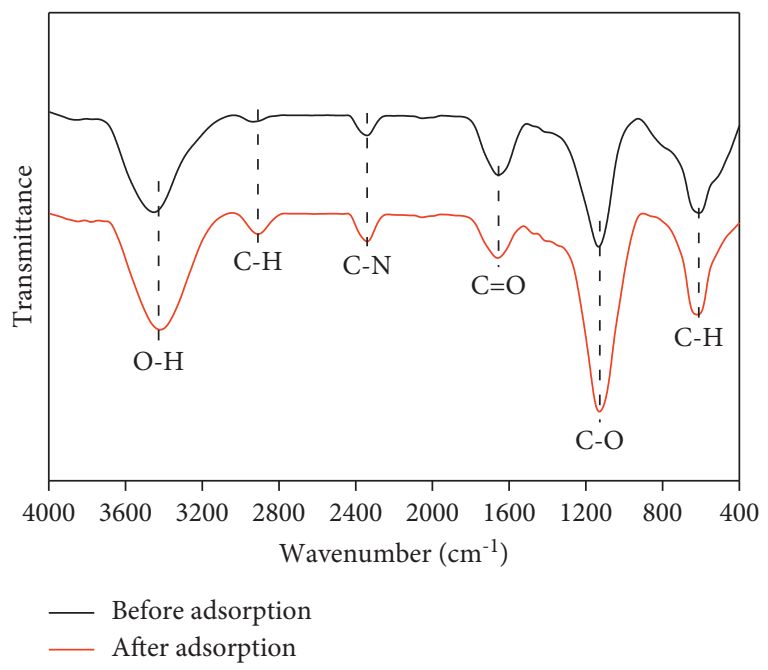

FIgURE 4: FT-IR spectra of the HTC-cornstalk.

TABLE 2: Ultimate analysis of samples.

\begin{tabular}{lcccc}
\hline \multirow{2}{*}{ Sample } & \multicolumn{4}{c}{ Ultimate analysis (wt\%) } \\
& $\mathrm{C} \%$ & $\mathrm{H} \%$ & $\mathrm{O} \%{ }^{*}$ & $\mathrm{~N} \%$ \\
\hline Cornstalk & 43.17 & 5.60 & 50.55 & 0.65 \\
HTC-cornstalk & 63.85 & 4.13 & 29.81 & 0.32 \\
\hline
\end{tabular}

* By difference.

increasing adsorbent dosage. Increasing the amount of HTC-cornstalk from $0.05 / 50$ to $0.2 / 50$ (g/mL) largely enhanced the elimination percentage of $\mathrm{Cr}(\mathrm{VI})$ ions from $36 \%$ to $98 \%$, resulted from the increase of the active sites which were available for the occupation of $\mathrm{Cr}$ (VI) ions. A further increase in the adsorbent dosage did not have any effect.

\subsubsection{Effect of Initial Cr (VI) Concentration and Contact}

Time. The adsorption performance of the HTC-cornstalk influenced by the initial $\mathrm{Cr}$ (VI) concentrations from 30 to $90 \mathrm{mg} / \mathrm{L}$ was studied at $35^{\circ} \mathrm{C}$ with $\mathrm{pH}=6$. Results are shown in Figure $7(\mathrm{a})$. The HTC-cornstalk dosage and the contacting duration were kept at $0.2 \mathrm{~g} / 50 \mathrm{~mL}, 90 \mathrm{~min}$, respectively. One was introduced that the removal efficiency and adsorbability of HTC increased along with the increase of Cr (VI) concentration. However, while the Cr (VI) concentration hit over $50 \mathrm{mg} / \mathrm{L}$, the removal efficiency steadily reduced as a consequence. With a high $\mathrm{Cr}$ (VI) ions concentration, the adsorption rate was restricted because the adsorption was saturated and the desorption rate was higher than adsorption [47].

Figure 7(b) shows the impact of contacting duration on the $\mathrm{Cr}$ (VI) adsorption within the aqueous solution with $50 \mathrm{mg} / \mathrm{L}$ in the initial Cr (VI) concentration under the same conditions. One was cleared that the adsorption procedure approached the equilibrium state within $150 \mathrm{~min}$ or less. The minor effect would appear even by further increasing the contacting duration. Desorption ratio of $\mathrm{Cr}$ (VI) ions and adsorption quantity in $150 \mathrm{~min}$ was reached almost $98 \%$, $12.29 \mathrm{mg} / \mathrm{g}$, respectively.

3.5. Adsorption Kinetic Analysis. A kinetic study on adsorption was carried out to reveal the adsorption rates and the controlling adsorption mechanism. Pseudo-first-order (equation (3)) and pseudo-second-order modes (equation (4)) are commonly used to fit experimental data [48]:

$$
\begin{aligned}
\ln \left(q_{e}-q\right) & =\ln q_{e}-k_{1} t, \\
\frac{t}{q} & =\frac{1}{k_{2} q_{e} q_{e}}+\frac{1}{q_{e}},
\end{aligned}
$$

where $k_{1}$ is the rate constant of the pseudo-first-order model $\left(\min ^{-1}\right), k_{2}$ is the rate constant of the pseudo-second-order model (g/mg. min), and $q_{e}$ and $q$ are the values of the amount adsorbed per unit mass at equilibrium and at any time $t$, respectively. The experimental data and the fitting by the two equations are shown in Figure 8, and the fitted kinetic parameters are given in Table 3 .

One emerged in Figure 8 and Table 3 that both models were well-fitted with the experimental data. Furthermore, the calculated adsorption capacities $\left(q_{e}, \mathrm{cal}\right)$ in the models were consistent with the experimental adsorption capacities $\left(q_{e}\right.$, exp). However, the pseudo-second-order model exhibited a higher correlation coefficient $\left(R^{2}\right)$ which was employed to estimate the consistency of the fitted models with experimental results than that of the pseudo-first-order model. Although, in consideration of a particular kinetic model, a relatively high $R^{2}$ was not irrefragable evidence of a better fitting [49]. The $\mathrm{Cr}$ (VI) adsorption onto HTCcornstalk in this work was considered that was apropos to the pseudo-second-order kinetic model.

3.6. Adsorption Isotherm Analysis. To investigate the Cr (VI) adsorbability of HTC, adsorption isotherms had been carried out with various initial concentrations of Cr (VI) (20, $30,40,50,60,70,80,90$, and $100 \mathrm{mg} / \mathrm{L})$ at different temperatures $\left(35^{\circ} \mathrm{C}, 45^{\circ} \mathrm{C}\right.$, and $\left.55^{\circ} \mathrm{C}\right)$.

Results had been fitted with Langmuir (5) and Freundlich (6) isotherm models:

$$
\begin{aligned}
\frac{c_{e}}{q_{e}} & =\frac{c_{e}}{q_{\max }}+\frac{1}{k_{1} q_{\max }}, \\
\lg q_{e} & =\lg \frac{c_{e}}{n}+\lg k,
\end{aligned}
$$

where $q_{e}$ refers to the quantity of adsorbed metal ions per unit mass of adsorbent $(\mathrm{mg} / \mathrm{g}), c_{e}$ represents the solute 

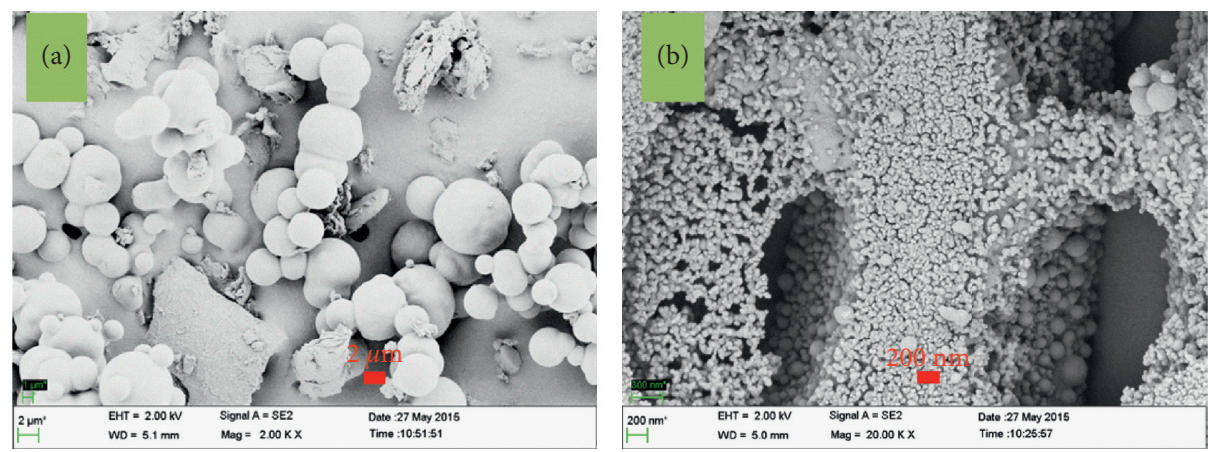

Figure 5: SEM images of HTC-cornstalk.

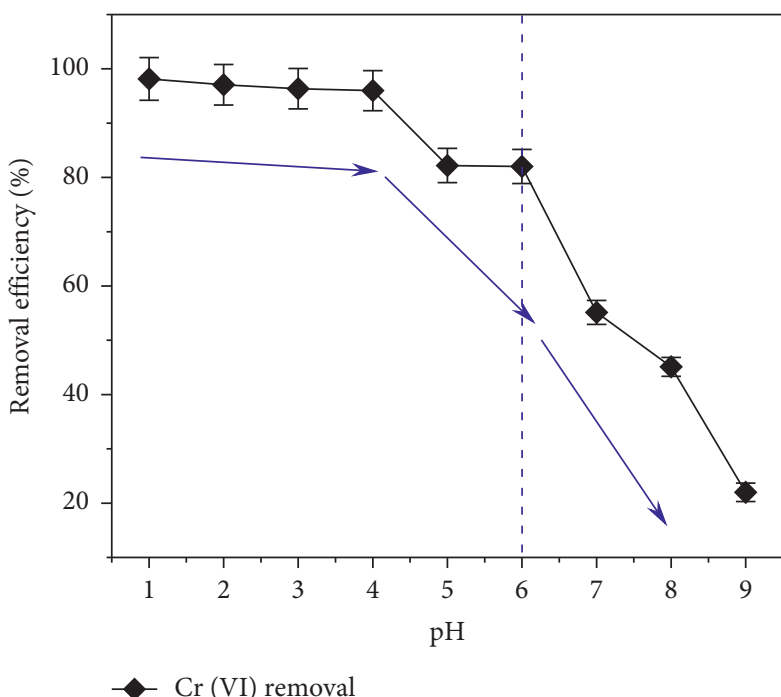

(a)

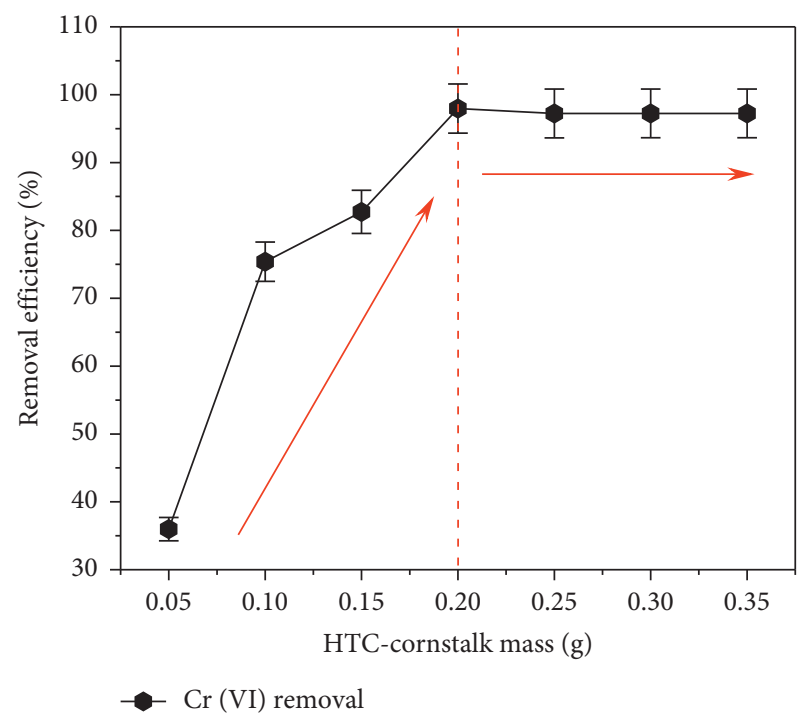

(b)

FIGURE 6: Effect of initial solution $\mathrm{pH}$ on the removal efficiency of $\mathrm{Cr}$ (VI) from aqueous solutions. (a) Volume, $50 \mathrm{~mL}$; agitation speed, $120 \mathrm{rpm}$; HTC dosage, $4 \mathrm{~g} / \mathrm{L}$; effect of initial solution of the HTC dosage on the removal efficiency of Cr (VI) from aqueous solutions. (b) pH, 6; volume, $50 \mathrm{~mL}$; agitation speed, $120 \mathrm{rpm}$; Cr (VI) concentration, $50 \mathrm{mg} / \mathrm{L}$; contact time, $90 \mathrm{~min}$.

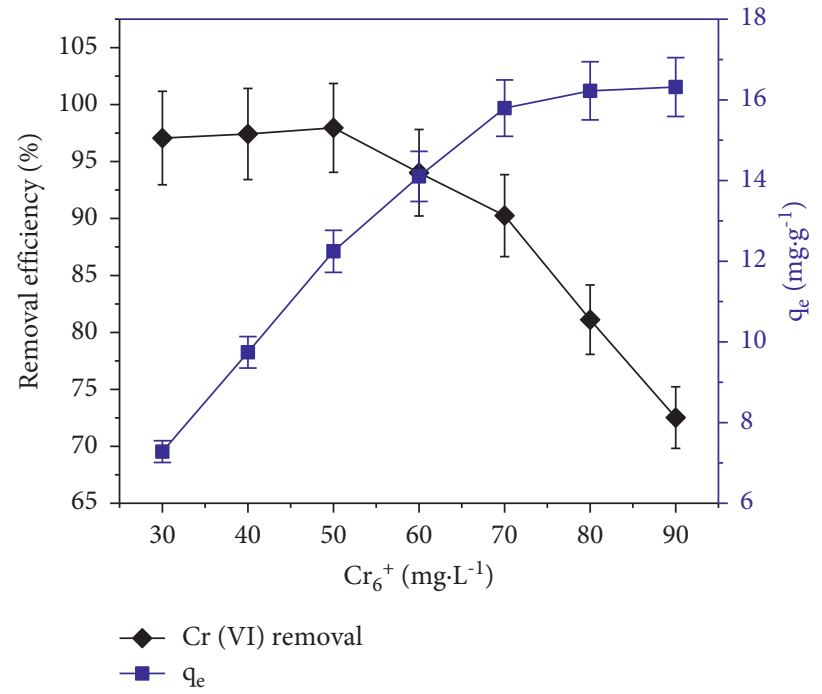

(a)

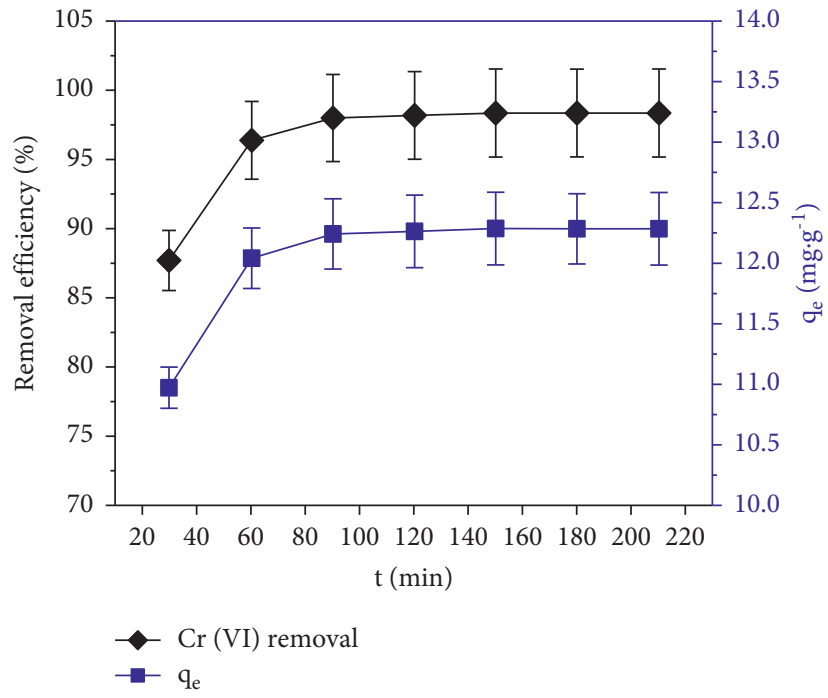

(b)

FIgURE 7: Effect of initial Cr (VI) concentration (a) and contacting duration (b) on the Cr (VI) adsorbability of HTC. 


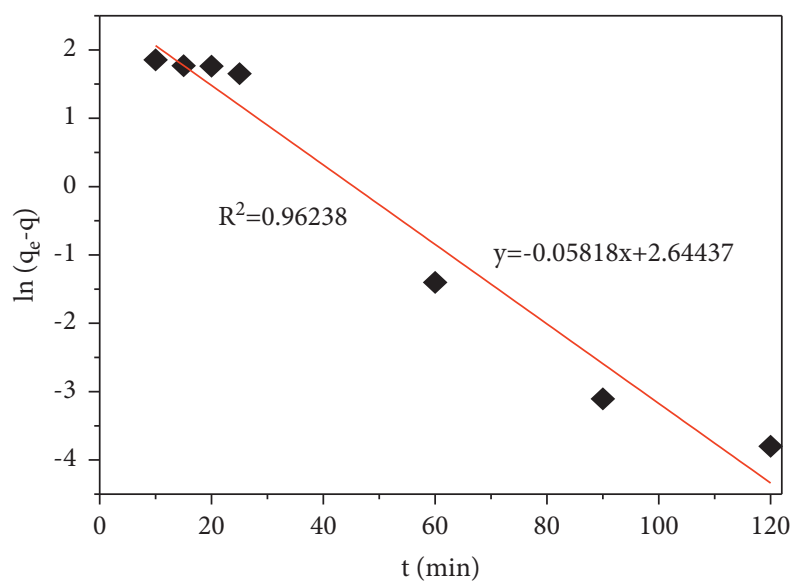

(a)

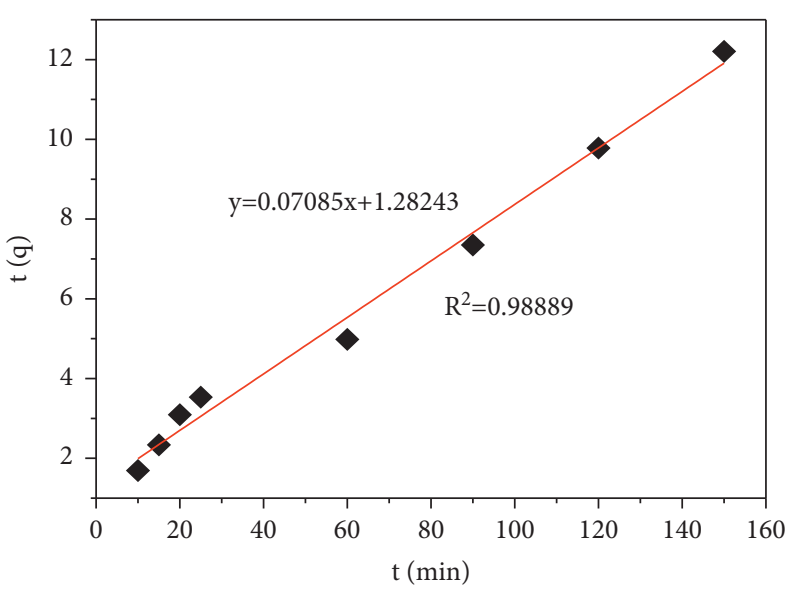

(b)

Figure 8: Pseudo-first-order kinetics (a) and pseudo-second-order kinetics (b) for Cr (VI) adsorption onto $\mathrm{HTC}$ at $35^{\circ} \mathrm{C}$ (initial Cr (VI) concentration $50 \mathrm{mg} / \mathrm{L})$.

TABLE 3: Adsorption kinetics parameters of Cr (VI) on HTC-cornstalk.

\begin{tabular}{lcccccc}
\hline \multirow{2}{*}{$q_{e \cdot \exp }(\mathrm{mg} / \mathrm{g})$} & \multicolumn{2}{c}{ Pseudo-first-order kinetic model } & \multicolumn{3}{c}{ Pseudo-second-order kinetic model } \\
& $q_{e \cdot \mathrm{cal}}(\mathrm{mg} / \mathrm{g})$ & $k_{1}\left(\mathrm{~min}^{-1}\right)$ & $R^{2}$ & $q_{e \cdot \mathrm{cal}}(\mathrm{mg} / \mathrm{g})$ & $k_{2}(\mathrm{~g} / \mathrm{mg} \mathrm{min})$ & $R^{2}$ \\
\hline 12.29 & 14.07 & 0.06 & 0.96 & 14.11 & 0.004 \\
\hline
\end{tabular}

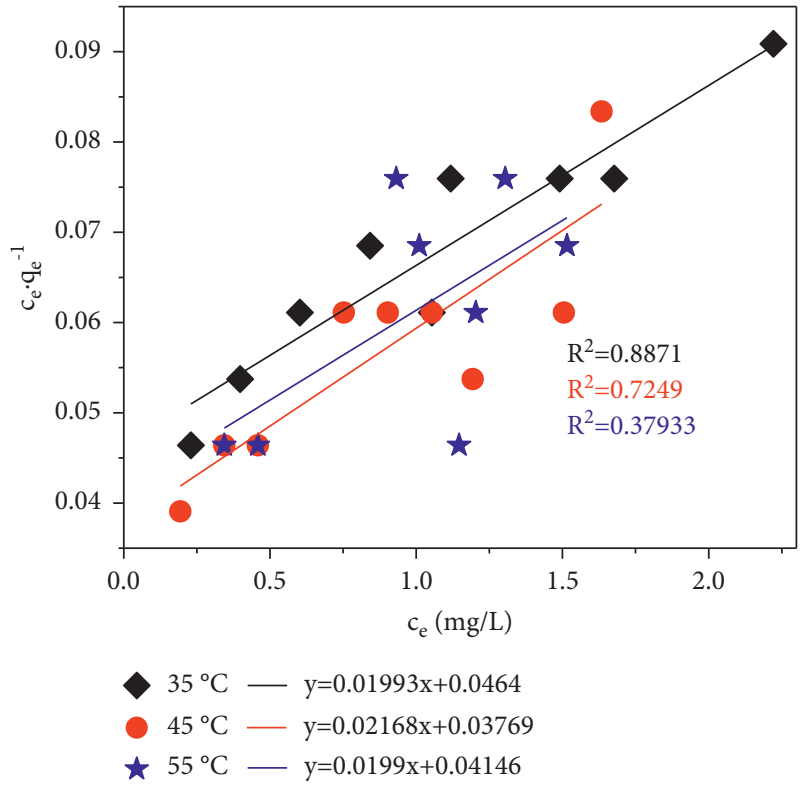

(a)

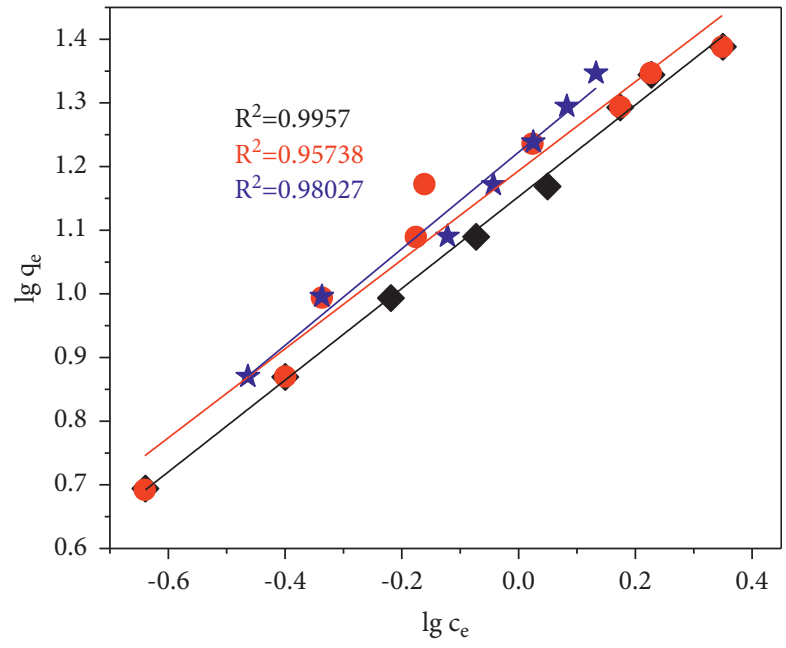

$35^{\circ} \mathrm{C}-\mathrm{y}=0.721 \mathrm{x}+1.153$
$45^{\circ} \mathrm{C}-\mathrm{y}=0.699 \mathrm{x}+1.193$
$\star 55^{\circ} \mathrm{C}-\mathrm{y}=0.759 \mathrm{x}+1.223$

(b)

FIGURE 9: Langmuir isotherm model (a) and Freundlich isotherm model (b) for Cr (VI) adsorption onto HTC.

concentration in the bulk solution $(\mathrm{mg} / \mathrm{L})$ at equilibrium state, $q_{\max }(\mathrm{mg} / \mathrm{g})$ and $k_{1}$ represent the Langmuir constants related to the saturated metal ions adsorbability and the adsorption free energy, respectively, and the constants $k$ and $n$ in the Freundlich model represent the strength and the distribution of the adsorptive bonds. Experimental data fitted with Langmuir and Freundlich equations are shown in Figure 9. Furthermore, the fitted results are given in Table 4 in detail.
As revealed above, $R^{2}$ values of higher than 0.9 were obtained in the Freundlich model which indicated an excellent consistency while fitting instead of many poor ones in the Langmuir model which were fitted at three different temperatures. Therefore, the Freundlich model was selected to express the $\mathrm{Cr}$ (VI) adsorption of HTC-cornstalk. Freundlich as an empirical equation had been employed to illustrate the exponential distribution sites, energies, and the 
TABLE 4: The parameters of the isotherm adsorption model.

\begin{tabular}{lccccc}
\hline Temperature $\left({ }^{\circ} \mathrm{C}\right)$ & \multicolumn{3}{c}{ Langmuir modes } & \multicolumn{3}{c}{ Freundlich models } \\
& $q_{\max }(\mathrm{mg} / \mathrm{g})$ & $K_{1}(\mathrm{~L} / \mathrm{mg})$ & $R^{2}$ & $K(\mathrm{mg} / \mathrm{g})$ & $1 / n$ \\
\hline 35 & 50.14640 & 0.42987 & 0.87281 & 14.49226 & 0.72818 \\
45 & 46.11816 & 0.57533 & 0.68560 & 15.63765 & 0.69809 \\
55 & 50.23585 & 0.48011 & 0.27588 & 17.50070 & 0.984531 \\
\hline
\end{tabular}

heterogeneity of the adsorbent surface [50]. The adsorption capacities $(\mathrm{K})$ increased with increasing temperatures. The values of $n$ at different temperatures are greater than unity, indicating favorable adsorption of $\mathrm{Cr}$ (VI) $[30,51]$.

\section{Conclusion}

A high-efficiency HTC adsorbent was successfully synthesized by the one-step hydrothermal method for the uptake of Cr (VI). The adsorption property of HTC was studied by varying $\mathrm{pH}$, HTC dosage, $\mathrm{Cr}$ (VI) concentration, and contact time. The Cr (VI) adsorption capability of HTC was pHdependent, which was favored with a low $\mathrm{pH}$ range. The $\mathrm{Cr}$ (VI) removal efficiency of HTC reached $98 \%$ under optimal experiment conditions. A pseudo-second-order kinetic model could describe $\mathrm{Cr}$ (VI) adsorption behavior on HTC well, while the Freundlich adsorption isotherm was more suitable for $\mathrm{Cr}$ (VI) adsorption onto the adsorbent. Thus, the HTC was a potentially effective and sustainable adsorbent for application in $\mathrm{Cr}(\mathrm{VI})$ removal from wastewater

\section{Data Availability}

The data used to support the findings of this study are included within the article.

\section{Conflicts of Interest}

The authors declare that they have no conflicts of interest.

\section{Acknowledgments}

This work was financially supported by the research fund of Provincial University Natural Science Research of Anhui (KJ2018A0093), the Provincial Natural Science Foundation of Anhui Province of Anhui (1908085QE189), the Postdoctoral Research Project of Anhui (2019B356), and the Talent introduction Project of Anhui University of Science and Technology (11885).

\section{References}

[1] H. Xiyili, S. Çetintaş, and D. Bingöl, "Removal of some heavy metals onto mechanically activated fly ash: modeling approach for optimization, isotherms, kinetics and thermodynamics," Process Safety and Environmental Protection, vol. 109, pp. 288-300, 2017.

[2] W. Qi, Y. Wang, M. Ji, Y. Zhao, and Z. Zhang, "Highly efficient adsorption of $\mathrm{Cr}(\mathrm{VI})$ by sakura leaves from aqueous solution," Chemistry Letters, vol. 44, no. 5, pp. 697-699, 2015.

[3] S. Li, L. Yu, K. Song, and D. Zhao, "Study on microscopic mechanism of activated carbon adsorption of benzene by molecular simulation technology," Chemistry Letters, vol. 49, no. 12, pp. 1452-1455, 2020.

[4] S. Rangabhashiyam, S. Sayantani, and P. Balasubramanian, "Assessment of hexavalent chromium biosorption using biodiesel extracted seeds of Jatropha sp., Ricinus sp. and Pongamia sp," International Journal of Environmental Science and Technology, vol. 16, no. 10, pp. 5707-5724, 2019.

[5] A. Hariharan, V. Harini, S. Sandhya, and S. Rangabhashiyam, "Waste musa acuminata residue as a potential biosorbent for the removal of hexavalent chromium from synthetic wastewater," Biomass Conversion and Biorefinery, pp. 1-14, 2020.

[6] A. H. M. G. Hyder, S. A. Begum, and N. O. Egiebor, "Adsorption isotherm and kinetic studies of hexavalent chromium removal from aqueous solution onto bone char," Journal of Environmental Chemical Engineering, vol. 3, no. 2, pp. 1329-1336, 2015.

[7] S. Nayak, S. Rangabhashiyam, P. Balasubramanian, and P. Kale, "A review of chromite mining in Sukinda valley of India: impact and potential remediation measures," International Journal of Phytoremediation, vol. 22, no. 8, pp. 804-818, 2020.

[8] S. Rangabhashiyam, N. Selvaraju, M. B. Raj, A. P. K. Muhammed, K. D. Amith, and E. R. Ushakumary, "Hydrous cerium oxide nanoparticles impregnated Enteromorpha sp. for the removal of hexavalent chromium from aqueous solutions," Journal of Environmental Engineering, vol. 142, no. 9, Article ID C4015016, 2016.

[9] V. Hasija, P. Raizada, P. Singh et al., "Progress on the photocatalytic reduction of hexavalent $\mathrm{Cr}$ (VI) using engineered graphitic carbon nitride," Process Safety and Environmental Protection, vol. 152, pp. 663-678, 2021.

[10] M. Ciopec, C. M. Davidescu, A. Negrea et al., “Adsorption studies of $\mathrm{Cr}$ (III) ions from aqueous solutions by DEHPA impregnated onto amberlite XAD7-factorial design analysis," Chemical Engineering Research and Design, vol. 90, no. 10, pp. 1660-1670, 2012.

[11] P. Choudhury, P. Mondal, S. Majumdar, S. Saha, and G. C. Sahoo, "Preparation of ceramic ultrafiltration membrane using green synthesized $\mathrm{CuO}$ nanoparticles for chromium (VI) removal and optimization by response surface methodology," Journal of Cleaner Production, vol. 203, pp. 511-520, 2018.

[12] P. Liu, T. Yan, J. Zhang, L. Shi, and D. Zhang, "Separation and recovery of heavy metal ions and salt ions from wastewater by 3D graphene-based asymmetric electrodes via capacitive deionization," Journal of Materials Chemistry A, vol. 5, no. 28, pp. 14748-14757, 2017.

[13] P. Ning, X. Lin, X. Wang, and H. Cao, "High-efficient extraction of vanadium and its application in the utilization of the chromium-bearing vanadium slag," Chemical Engineering Journal, vol. 301, pp. 132-138, 2016.

[14] J. Yang, M. Yu, and W. Chen, "Adsorption of hexavalent chromium from aqueous solution by activated carbon prepared from longan seed: kinetics, equilibrium and thermodynamics," Journal of Industrial and Engineering Chemistry, vol. 21, pp. 414-422, 2015. 
[15] D. Yadav, S. Rangabhashiyam, P. Verma et al., "Environmental and health impacts of contaminants of emerging concerns: recent treatment challenges and approaches," Chemosphere, vol. 272, Article ID 129492, 2021.

[16] R. Selvasembian, W. Gwenzi, N. Chaukura, and S. Mthembu, "Recent advances in the polyurethane-based adsorbents for the decontamination of hazardous wastewater pollutants," Journal of Hazardous Materials, vol. 417, Article ID 125960, 2021.

[17] S. Rangabhashiyam, K. Vijayaraghavan, A. H. Jawad, P. Singh, and P. Singh, "Sustainable approach of batch and continuous biosorptive systems for praseodymium and thulium ions removal in mono and binary aqueous solutions," Environmental Technology \& Innovation, vol. 23, Article ID 101581, 2021.

[18] H. Deveci and Y. Kar, "Adsorption of hexavalent chromium from aqueous solutions by bio-chars obtained during biomass pyrolysis," Journal of Industrial and Engineering Chemistry, vol. 19, no. 1, pp. 190-196, 2013.

[19] M. López-García, P. Lodeiro, R. Herrero, and M. E. Sastre De Vicente, "Cr(VI) removal from synthetic and real wastewaters: the use of the invasive biomass Sargassum muticum in batch and column experiments," Journal of Industrial and Engineering Chemistry, vol. 18, no. 4, pp. 1370-1376, 2012.

[20] H. Wang, Z. Xu, A. Kohandehghan et al., "Interconnected carbon nanosheets derived from hemp for ultrafast supercapacitors with high energy," ACS Nano, vol. 7, no. 6, pp. 5131-5141, 2013.

[21] T. Yang, C. Han, J. Tang, and Y. Luo, "Removal performance and mechanisms of $\mathrm{Cr}(\mathrm{VI})$ by an in-situ self-improvement of mesoporous biochar derived from chicken bone," Environmental Science and Pollution Research, vol. 27, no. 5, pp. 5018-5029, 2020.

[22] D. Xia, H. Li, Z. Chen et al., "Mesoporous activated biochar for as(III) adsorption: a new utilization approach for biogas residue," Industrial \& Engineering Chemistry Research, vol. 58, no. 38, pp. 17859-17870, 2019.

[23] Y. Gao, Y. Zhang, A. Li, and L. Zhang, "Facile synthesis of high-surface area mesoporous biochar for energy storage via in-situ template strategy," Materials Letters, vol. 230, pp. 183-186, 2018.

[24] X. Chen, X. Ma, X. Peng, Y. Lin, J. Wang, and C. Zheng, "Effects of aqueous phase recirculation in hydrothermal carbonization of sweet potato waste," Bioresource Technology, vol. 267, pp. 167-174, 2018.

[25] P. Gao, Y. Zhou, F. Meng et al., "Preparation and characterization of hydrochar from waste eucalyptus bark by hydrothermal carbonization," Energy, vol. 97, pp. 238-245, 2016.

[26] X. Cao and W. Harris, "Properties of dairy-manure-derived biochar pertinent to its potential use in remediation," Bioresource Technology, vol. 101, no. 14, pp. 5222-5228, 2010.

[27] K. G. Roberts, B. A. Gloy, S. Joseph, N. R. Scott, and J. Lehmann, "Life cycle assessment of biochar systems: estimating the energetic, economic, and climate change potential," Environmental Science \& Technology, vol. 44, no. 2, pp. 827-833, 2010.

[28] P. Abhijeet, G. Swagathnath, S. Rangabhashiyam, M. Asok Rajkumar, and P. Balasubramanian, "Prediction of pyrolytic product composition and yield for various grass biomass feedstocks," Biomass Conversion and Biorefinery, vol. 10, no. 3, pp. 663-674, 2020.

[29] S. Chen, J. Wang, Z. Wu et al., "Enhanced Cr(VI) removal by polyethylenimine- and phosphorus-codoped hierarchical porous carbons," Journal of Colloid and Interface Science, vol. 523, pp. 110-120, 2018.
[30] J. Anandkumar and B. Mandal, "Removal of Cr(VI) from aqueous solution using bael fruit (Aegle marmelos correa) shell as an adsorbent," Journal of Hazardous Materials, vol. 168, no. 2, pp. 633-640, 2009.

[31] M. Dakiky, M. Khamis, A. Manassra, and M. Mer'Eb, “Selective adsorption of chromium(VI) in industrial wastewater using low-cost abundantly available adsorbents," Advances in Environmental Research, vol. 6, no. 4, pp. 533-540, 2002.

[32] G. Swagathnath, S. Rangabhashiyam, S. Murugan, and P. Balasubramanian, "Influence of biochar application on growth of Oryza sativa and its associated soil microbial ecology," Biomass Conversion and Biorefinery, vol. 9, no. 2, pp. 341-352, 2019.

[33] F. Wang, W. Yi, D. Zhang, Y. Liu, X. Shen, and Y. Li, "Anaerobic co-digestion of corn stover and wastewater from hydrothermal carbonation," Bioresource Technology, vol. 315, Article ID 123788, 2020.

[34] Y. Ma, Z. Zhao, Z. Shen, Q. Cai, H. Ji, and L. Meng, "Hydrothermal carbonation carbon-coated cds nanocomposite with enhanced photocatalytic activity and stability," Catalysts, vol. 7, no. 7, p. 194, 2017.

[35] T. Chi, J. Zuo, and F. Liu, "Performance and mechanism for cadmium and lead adsorption from water and soil by corn straw biochar," Frontiers of Environmental Science \& Engineering, vol. 11, no. 2, p. 15, 2017.

[36] R. Z. Wang, D. L. Huang, Y. G. Liu et al., "Investigating the adsorption behavior and the relative distribution of $\mathrm{Cd} 2+$ sorption mechanisms on biochars by different feedstock," Bioresource Technology, vol. 261, pp. 265-271, 2018.

[37] M. A. Islam, I. A. W. Tan, A. Benhouria, M. Asif, and B. H. Hameed, "Mesoporous and adsorptive properties of palm date seed activated carbon prepared via sequential hydrothermal carbonization and sodium hydroxide activation," Chemical Engineering Journal, vol. 270, pp. 187-195, 2015.

[38] R. J. White, C. Antonio, V. L. Budarin, E. Bergström, J. Thomas-Oates, and J. H. Clark, "Polysaccharide-derived carbons for polar analyte separations," Advanced Functional Materials, vol. 20, no. 11, pp. 1834-1841, 2010.

[39] J. Chen, P. Wang, Y. Cao, B. Guo, and D. Zhang, "Impact of pyrolytic temperature and acid wash on adsorption kinetics of carbamazepine on biochar," Environmental Chemistry, vol. 35, no. 07, pp. 1461-1467, 2016.

[40] D. Suteu, C. Zaharia, and T. Malutan, "Equilibrium, kinetic, and thermodynamic studies of basic blue 9 dye sorption on agro-industrial lignocellulosic materials," Open Chemistry, vol. 10, no. 6, pp. 1913-1926, 2012.

[41] D. Ma, M. Zhang, G. Xi, J. Zhang, and Y. Qian, "Fabrication and characterization of ultralong $\mathrm{Ag} / \mathrm{C}$ nanocables, carbonaceous nanotubes, and chainlike $\beta$-Ag2Se nanorods inside carbonaceous nanotubes," Inorganic Chemistry, vol. 45, no. 12 , pp. 4845-4849, 2006.

[42] A. Jain, R. Balasubramanian, and M. P. Srinivasan, "Production of high surface area mesoporous activated carbons from waste biomass using hydrogen peroxide-mediated hydrothermal treatment for adsorption applications," Chemical Engineering Journal, vol. 273, pp. 622-629, 2015.

[43] M. A. Islam, A. Benhouria, M. Asif, and B. H. Hameed, "Methylene blue adsorption on factory-rejected tea activated carbon prepared by conjunction of hydrothermal carbonization and sodium hydroxide activation processes," Journal of the Taiwan Institute of Chemical Engineers, vol. 52, pp. 57-64, 2015. 
[44] M. M. Titirici, M. Antonietti, and A. Thomas, "A generalized synthesis of metal oxide hollow spheres using a hydrothermal approach," Chemistry of Materials, vol. 18, no. 16, pp. 3808-3812, 2006.

[45] M. K. Mondal, "Removal of $\mathrm{Pb}$ (II) from aqueous solution by adsorption using activated tea waste," Korean Journal of Chemical Engineering, vol. 27, no. 1, pp. 144-151, 2010.

[46] Z. Liu, A. Zhou, G. Wang, and X. Zhao, "Adsorption behavior of methyl orange onto modified ultrafine coal powder," Chinese Journal of Chemical Engineering, vol. 17, no. 6, pp. 942-948, 2009.

[47] X. S. Wang and Z. Z. Li, "Removal of Cr (VI) from aqueous solution by newspapers," Desalination, vol. 249, no. 1 , pp. 175-181, 2009.

[48] F. Gorzin and A. A. Ghoreyshi, "Synthesis of a new low-cost activated carbon from activated sludge for the removal of $\mathrm{Cr}$ (VI) from aqueous solution: equilibrium, kinetics, thermodynamics and desorption studies," Korean Journal of Chemical Engineering, vol. 30, no. 8, pp. 1594-1602, 2013.

[49] Kithome and Mussolini, "Reducing nitrogen losses during composting of poultry manure using the natural zeolite clinoptilolit," Dissertation Abstracts International, Vol. 59-05, The University of British Columbia, Vancouve, Canada, 1998.

[50] Y. Wang, B. Du, J. Wang, Y. Wang, H. Gu, and X. Zhang, "Synthesis and characterization of a high capacity ionic modified hydrogel adsorbent and its application in the removal of $\mathrm{Cr}(\mathrm{VI})$ from aqueous solution," Journal of Environmental Chemical Engineering, vol. 6, no. 6, pp. 6881-6890, 2018.

[51] X. S. Wang, Y. P. Tang, and S. R. Tao, "Removal of Cr (VI) from aqueous solutions by the nonliving biomass of alligator weed: kinetics and equilibrium," Adsorption, vol. 14, no. 6, pp. 823-830, 2008. 